Communication

\title{
Stereotypic Behavior in Fattening Bulls
}

\author{
Laura Schneider *, Nicole Kemper® and Birgit Spindler \\ Institute for Animal Hygiene, Animal Welfare and Animal Behavior, University of Veterinary Medicine \\ Hannover, Foundation, D-30173 Hannover, Germany; nicole.kemper@tiho-hannover.de (N.K.); \\ birgit.spindler@tiho-hannover.de (B.S.) \\ * Correspondence: laura.schneider@tiho-hannover.de; Tel.: +49-511-856-8963
}

Received: 5 December 2019; Accepted: 22 December 2019; Published: 24 December 2019

Simple Summary: Cattle housed under intensive housing conditions may display stereotypic behavior like manipulating objects or body parts of conspecifics with their tongue or rolling and unrolling their tongue repeatedly (so-called tongue playing). These stereotypies may indicate restricted welfare. To our knowledge, there are no studies on the occurrence of stereotypies in fattening cattle. Therefore, this study aimed to analyze the prevalence of stereotypies in 243 fattening bulls housed under different conditions in straw-bedded pens in groups of 14,16, 22, and 33 animals. The animals in one housing system were fed six times per day, the other animals twice per day. The animals' behavior was observed at three different stages during the fattening period. Two hundred and thirty-four of 243 bulls were observed performing stereotypies at least once. In the different housing systems, an average of 0.2 to 0.9 stereotypies occurred per animal and hour. The most common stereotypy was manipulating objects, followed by tongue playing and manipulating conspecifics. These results show that stereotypies are a common problem in fattening cattle, occurring frequently under different housing conditions. As this may indicate restrictions in welfare, further studies on stereotypies in fattening cattle are needed in order to detect the reasons for their occurrence.

Abstract: The occurrence of stereotypies in captive animals may indicate restrictions in animal welfare. In cattle, common stereotypies are tongue playing, manipulation of objects, or conspecifics. However, to our knowledge, the occurrence of stereotypies in fattening cattle was only analyzed in studies several decades old. Therefore, this study aimed to analyze the prevalence of stereotypies in fattening bulls housed in different systems. On three German fattening farms, a total of 243 fattening bulls housed in groups of 14,16, 22, and 33 animals in straw-bedded pens were observed. Behavioral observations were performed via video recordings during three observation periods distributed over the whole fattening period, using a scan sampling technique. In 234 of 243 bulls, stereotypies were observed at least once. During $15.9 \pm 2.4 \%$ of the scan intervals, stereotypies were observed in at least one animal per pen. Average numbers of stereotypies per animal and hour ranged from 0.2 to 0.9 . The most common stereotypy was manipulating objects, followed by tongue playing and manipulating conspecifics. These results indicate that stereotypies are highly prevalent in fattening bulls under current housing conditions. They underline the need for further studies to analyze the causation of stereotypies in order to reduce their frequency.

Keywords: oral stereotypies; fattening cattle; abnormal behavior; tongue playing; oral manipulation

\section{Introduction}

The development of stereotypies in captive animals has already been described as an indicator of restrictions in animal welfare several decades ago [1-3]. According to more recent studies, it is caused by deficits in housing or husbandry, leading to frustration of natural behavior patterns, repeated 
attempts to deal with problems, and/ or central nervous system dysfunction [4]. Consequently, the occurrence of stereotypies possibly indicates that one of the Farm Animal Welfare Council's Five Freedoms, namely freedom to express normal behavior, is restricted [5].

According to Broom [2], the welfare of an individual is compromised if it performs stereotypies for more than $10 \%$ of its waking life. Wiepkema et al. [3] suggested that stereotypies occurring in more than $1 \%$ to $5 \%$ of a group of animals could be interpreted as an indicator of compromised animal welfare in a particular housing system.

In cattle, common stereotypies are tongue playing, object licking, and bar biting as well as manipulating different body parts of conspecifics [6-8]. Wiepkema et al. [3] defined tongue playing as stereotyped behavior as it is fixed in form and orientation and it is performed repetitively without any obvious function. In contrast, object licking, bar biting, and manipulating body parts of conspecifics are classified as redirected behaviors, being performed due to the absence of adequate substrate and/or occurring very often or intense [3]. In this study, according to Mason [4], redirected behaviors were also interpreted as stereotypies, following the definition of stereotypic behavior as "repetitive behavior induced by frustration, repeated attempts to cope, and/or central nervous system dysfunction". There are several studies on the occurrence of these stereotypies in calves [9-16], but studies on the occurrence of stereotypies in adult cattle are rare. Nonetheless, available studies agree concerning the high prevalence of stereotypies: In dairy cows, Redbo et al. [17] observed stereotypies in 40 of 95 animals, while Redbo et al. [18] described them in 27 of 37 animals. In a study on heifers, depending on feed, 16 to 44 of 48 animals were observed performing stereotypies [19]. In beef cattle, there are no studies available on the incidence and prevalence of stereotypic behavior according to the EFSA (European Food Safety Authority) Panel on Animal Health and Welfare [20]. Indeed, our literature review only revealed studies published more than 25 years ago [12-23]. However, these studies also report a high prevalence of stereotypies with different types of oral stereotypies occurring in all observed bulls.

According to the evaluations of Broom [2] and Wiepkema et al. [3], the literature figures for the prevalence of stereotypies in adult cattle are alarming. As there are no studies on fattening bulls in current housing environments to our knowledge, there is no information available on the current prevalence of stereotypies in fattening cattle. Therefore, this study surveyed the occurrence of stereotypies in fattening bulls housed under different housing conditions.

\section{Materials and Methods}

The study was carried out in accordance with German legislation, the German Animal Welfare Act (German designation: TierSchG) [24], national requirements for animal husbandry (German designation: TierSchNutztV) [25], the Animal Protection Guideline for Fattening Cattle of Lower Saxony, Germany [26], as well as the Council of Europe Convention on the Protection of Animals Kept for Farming Purposes and its recommendations concerning cattle [27]. The study was reviewed and it received approval from the Animal Welfare Officer of the University of Veterinary Medicine Hannover, Foundation (TVO-2017-B5).

The animals observed in the study were 243 Simmental bulls housed on three commercial fattening farms in Germany (Lower Saxony and North Rhine-Westphalia). The bulls were housed in straw-bedded pens in four different housing systems, including groups of 14 (G14), 16 (G16), 22 (G22), and 33 animals (G33). Detailed information on housing, management, and feed composition are listed in Table 1. In G14, the bulls were fed a total mixed ration (TMR) six times a day using an automatic feeding system (AFS; feeding robot Triomatic HP 2 300, Trioliet, Oldenzaal, the Netherlands). In the other housing systems, feed was delivered twice a day using conventional feed-mixer wagons. In addition, feed was pushed up towards the feed barrier several times a day in all systems. The animal/feeding-place ratio was approximately 2:1 in all groups [26]. Water was available ad libitum via two (in G33 four) drinking troughs per pen. Fresh straw was distributed daily with a straw blower. The animals in G33 on farm 3 received additional straw via hayracks. 
Table 1. Housing information for the observed animals. TMR $=$ total mixed ration, $\mathrm{DM}=$ dry matter.

\begin{tabular}{|c|c|c|c|}
\hline Farm Information & Farm 1 & Farm 2 & Farm 3 \\
\hline Number of bulls per group & 14 & $22^{1}$ & 16,33 \\
\hline Space allowance per bull $\left(\mathrm{m}^{2}\right)$ & 4 & $3.5 / 4.4^{2}$ & 4.5 \\
\hline $\begin{array}{l}\text { Feeding system (number of feed } \\
\text { deliveries per day) }\end{array}$ & $\begin{array}{l}\text { Automatic feeding } \\
\text { system (6) }\end{array}$ & $\begin{array}{l}\text { conventional feed-mixer } \\
\text { wagon (2) }\end{array}$ & $\begin{array}{c}\text { conventional feed-mixer } \\
\text { wagon ( } 2 \text { ) }\end{array}$ \\
\hline Groups considered in this study & 4 & 4 & 2,2 \\
\hline \multicolumn{4}{|c|}{ Ingredients of the TMR (\%) } \\
\hline Maize silage & 72.5 & 85.5 & 84.1 \\
\hline Grass silage & - & 0.9 & 7.7 \\
\hline Barley straw & 1.0 & - & - \\
\hline Potatoes & 12.7 & 4.5 & - \\
\hline Concentrated feed/grain & 13.2 & 8.4 & 7.7 \\
\hline Mineral and vitamin mix & 0.6 & 0.7 & 0.6 \\
\hline \multicolumn{4}{|c|}{ Chemical composition of the TMR } \\
\hline $\mathrm{DM}(\%)$ & 40.5 & 44.5 & 35.9 \\
\hline Crude protein (\% DM) & 12.9 & 11.6 & 10.5 \\
\hline Crude ash $(\% \mathrm{DM})$ & 6.1 & 6.0 & 3.8 \\
\hline Crude fat (\% DM) & 2.3 & 2.1 & 3.2 \\
\hline Crude fiber (\% DM) & 16.1 & 14.2 & 16.3 \\
\hline Nitrogen free extractives (\% DM) & 62.6 & 66.1 & 66.2 \\
\hline $\mathrm{pH}$ & 4.6 & 4.8 & 3.9 \\
\hline \multicolumn{4}{|c|}{ Particle size distribution of the TMR (\%) } \\
\hline $\begin{array}{l}\text { Particles remained by } 19 \mathrm{~mm} \text { sieve } \\
\text { (long) }\end{array}$ & 10.9 & 7.9 & 3.8 \\
\hline $\begin{array}{l}\text { Particles retained by } 8 \mathrm{~mm} \text { sieve } \\
\text { (medium) }\end{array}$ & 50.5 & 58.4 & 57.6 \\
\hline Particles on bottom pen (short) & 38.6 & 33.7 & 38.6 \\
\hline
\end{tabular}

The animals had arrived at the farms at about six months of age, originating from different farms. They were assigned to groups, these remaining constant until the end of fattening. For the study, four groups of G14 and G22 and two groups of G16 and G33 each were selected. Data acquisition began when the final groups had existed for at least four weeks. It was performed during three observation periods (OP) at an average age of nine months (OP1), 13 to 14 months (OP2), and 17 months (OP3). One of the G33-groups was only observed in OP2 and OP3.

Behavioral observations were performed analyzing video recordings. The animals were videotaped with one video camera per pen (EQ900F, EverFocus Electronics Corporation, Taipei, Taiwan) and an eight-channel hybrid recorder (AXR-108, Monacor International GmbH and Co. KG, Bremen, Germany). The cameras were located above the pens, capturing one full pen each. Individual animals were identified by the color and pattern of their fur. Video analyses were performed using the program Interact (Version 17.0.1.2, Mangold International GmbH, Arnstorf, Germany) for observational research. The activity of the animals was observed for $48 \mathrm{~h}$ per OP using a scan sampling technique [28]. At two-minute intervals from $05: 30 \mathrm{~h}$ to 21:00 $\mathrm{h}$ and 10-min intervals during the night (21:00 $\mathrm{h}$ to 05:30 $\mathrm{h}$ ), the number of animals performing stereotypies was recorded. Thereby, it was differed between tongue playing, manipulating objects, and manipulating conspecifics. Tongue playing was defined as a curling and uncurling of the tongue inside or outside the mouth [6]. Manipulating objects referred to object licking (licking, nibbling, sucking, or biting any object, except for feed and straw) [10] as well as bar biting (clamping jaws around a bar and moving head back and forth while chewing on bar) [6]. Manipulating conspecifics was defined as an animal taking a part of the body of a conspecific into its mouth and sucking or biting it [10]. In a second step of video analysis, the behavior of all animals was scanned at individual level at 10-min intervals from $05: 30 \mathrm{~h}$ to 21:00 $\mathrm{h}$ on three consecutive days per 
OP, using a combination of scan sampling and focal animal sampling [28]. The recorded behavioral patterns were consistent with those of the evaluation at herd level.

The data were analyzed descriptively, using Microsoft Excel (2010). At herd level, the percentage of animals performing stereotypies was averaged per interval. In addition, the percentage of scan intervals between 06:00 $\mathrm{h}$ and 23:00 $\mathrm{h}$ with stereotypies being observed in at least one animal was calculated per group and OP. Furthermore, the average number of stereotypies per animal and hour was calculated per OP. At the individual level, the percentage of animals observed performing each stereotypic pattern at least once was calculated per group.

\section{Results}

Stereotypies were observed in 234 of 243 bulls (96.3\%; Figure 1). In G14 and G16, all animals were found to perform stereotypies, while in G22, all but two, and in G33, all but seven animals were affected. Tongue playing was observed in the greatest percentage of animals, ranging from $81.8 \%$ (G33) to $95.5 \%$ (G22). Manipulating objects and conspecifics followed with percentages of $42.4 \%$ to $92.9 \%$ and $34.9 \%$ to $71.9 \%$, respectively.

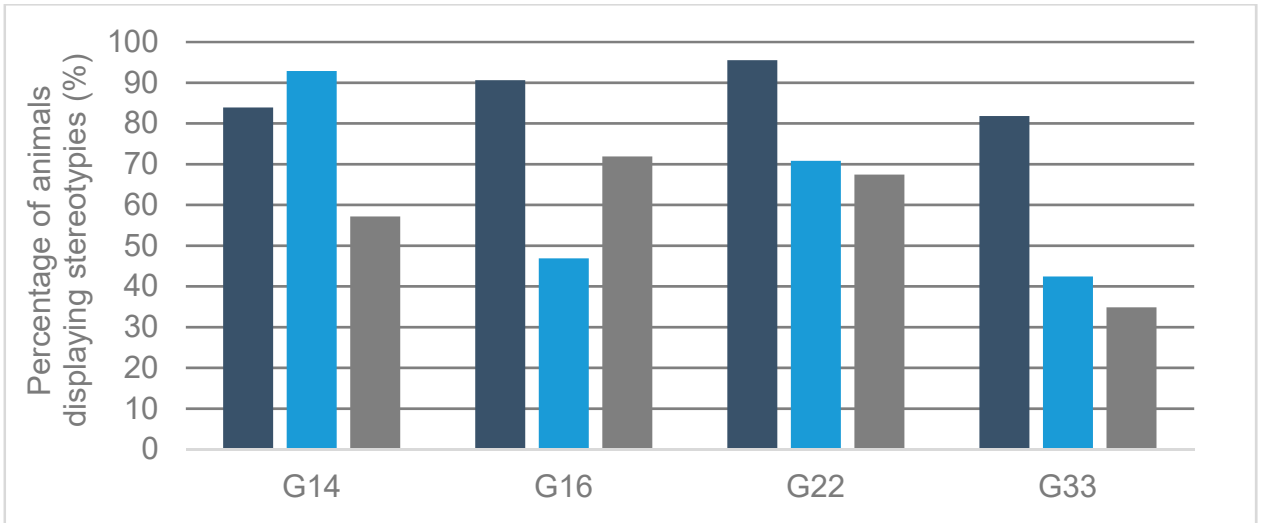

Figure 1. Percentage of animals observed displaying different stereotypic behavioral patterns in different housing systems. G14 = groups of 14 animals, G16 = groups of 16 animals, G22 = groups of 22 animals, G33 = groups of 33 animals. Dark blue = tongue playing, light blue = manipulating objects, gray $=$ manipulating conspecifics.

In total, stereotypies were observed in at least one animal during an average percentage of $15.9 \pm$ $2.4 \%$ of the scan intervals from $06: 00 \mathrm{~h}$ to $23: 00 \mathrm{~h}$. Differentiating between the four housing systems, these percentages were slightly lower in G14 $(14.7 \pm .2 .6 \%)$ and G33 $(14.9 \pm 2.1 \%)$ than in G16 $(17.0 \pm$ $1.8 \%)$ and G22 (16.9 \pm 2.4$)$.

The average number of stereotypies observed per animal and hour was calculated per housing system and OP (Figure 2). Values ranged from 0.2 (G16, OP2) to 0.9 (G16, OP1). The most common stereotypy was manipulation of objects in all housing systems and OP, occurring on average 0.1 to 0.5 times per animal and hour. Tongue playing and manipulation of conspecifics followed, occurring 0.01 to 0.2 times and 0.02 to 0.2 times per animal and hour. Developments over the course of the fattening period varied between the different housing systems. In G22, there was a linear decrease in the average number of stereotypies per animal and hour from OP1 to OP3. In consistence, the average number of stereotypies in G16 was clearly higher in OP1 than in the following OP, but values slightly increased again from OP2 to OP3. In G14, there was no clear development over the course of the fattening period and in G33, the number of stereotypies slightly increased with OP. 


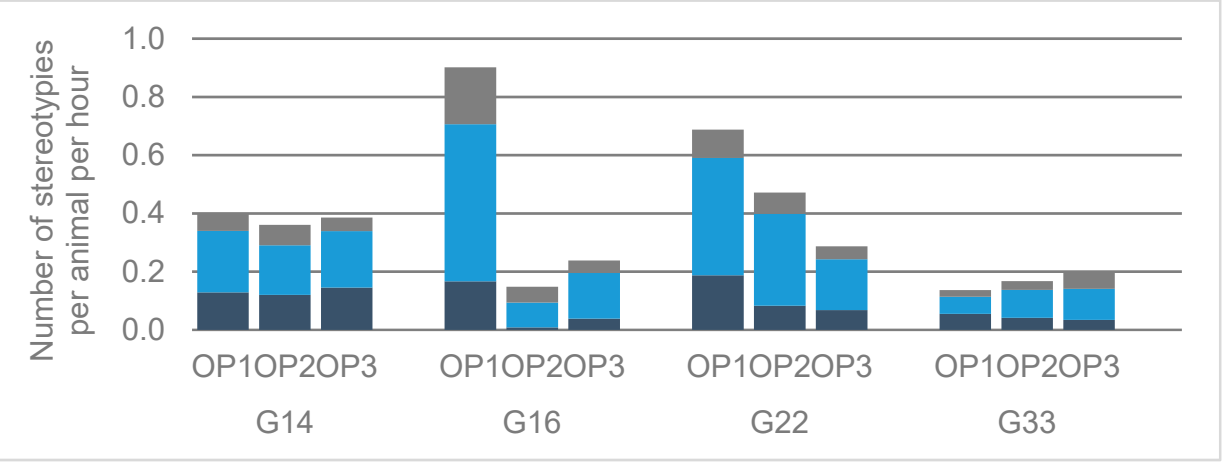

Figure 2. Averaged number of stereotypies observed per animal and hour in different housing systems and observation periods (OP). OP1 = First OP (age of the animals: Eight to nine months), OP2 = second OP (13 to 14 months of age), OP3 = third OP (17 months of age), G14 = groups of 14 animals, G16 = groups of 16 animals, G22 = groups of 22 animals, G33 = groups of 33 animals. Dark blue = tongue playing, light blue $=$ manipulating objects, gray $=$ manipulating conspecifics .

The averaged percentage of animals performing stereotypies over the course of the day are displayed in Figure 3. Highest values were observed in all housing systems during the daytime, between 07:00 $\mathrm{h}$ and 21:00 $\mathrm{h}$. During the night, the averaged percentage of animals performing stereotypies never exceeded $2 \%$ and even periods without any animals performing stereotypies were observed. Maximum values ranged from $4.2 \%$ in G33 to $7.8 \%$ in G16. In all housing systems with conventional feeding systems delivering feed twice a day (G16, G22, and G33), maximum values occurred during the periods of feed delivery.
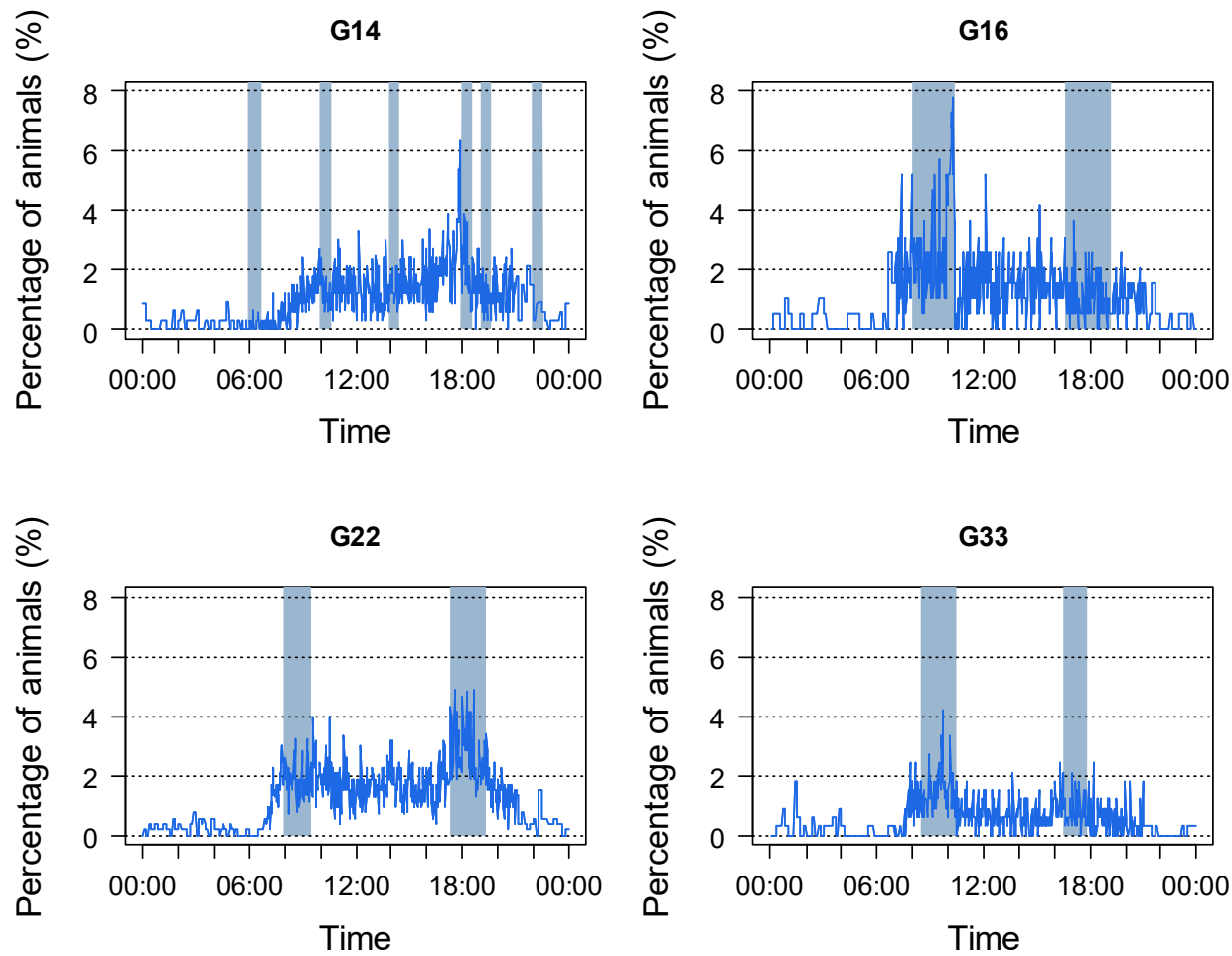

Figure 3. Averaged percentage of animals per pen performing stereotypies over a $24 \mathrm{~h}$ period. G14 = groups of 14 animals, G16 = groups of 16 animals, G22 = groups of 22 animals, G33 = groups of 33 animals. Blue areas = periods of feed delivery. Data were averaged for each interval for three observation periods of two days each and two groups of G16 and G33 as well as four groups of G14 and G22 each. 


\section{Discussion}

This study aimed to survey the prevalence of stereotypies in fattening cattle. It can be concluded that the prevalence is high in fattening bulls housed in various housing systems. Only 9 of 243 bulls were not observed performing stereotypies. All other animals were observed at least once displaying tongue playing or manipulating objects or conspecifics. Consequently, the results of the current study do not indicate a reduced prevalence of stereotypies in fattening cattle in comparison to the studies that were published several decades ago: Sambraus et al. [22] observed 55 fattening bulls aged between 8 and 13.5 months that all displayed tongue playing at least once. Manipulating objects even was observed at least once per day in all bulls, and manipulation of different body parts of conspecifics in up to $49 \%$ of the bulls. Graf [21] analyzed the occurrence of manipulating objects and conspecifics in 465 fattening bulls aged between six and nine months and fed with rations with or without hay. He observed the manipulation of objects in $99.1 \%$ to $100 \%$ of the bulls and the manipulation of conspecifics in $25.2 \%$ to $39.4 \%$ of the bulls. In the present study, there was no stereotypic behavior that was observed in all animals. However, the highest percentage for any one stereotypic behavior was observed for tongue playing with $81.8 \%$ to $95.5 \%$ of the animals in the different housing systems, and manipulation of objects also occurred in a considerable percentage of the animals with up to $92.9 \%$ of the bulls in G14 exhibiting this behavior. Manipulation of objects in the remaining housing systems as well as manipulation of conspecifics occurred in at least $34.9 \%$ and up to $71.9 \%$ of the animals. Consequently, the percentage of animals performing stereotypies clearly exceeded $1 \%$ to $5 \%$, suggested by Wiepkema et al. [3] as a critical value. Thus, the observed prevalence of stereotypies possibly indicates compromised animal welfare.

According to Broom [2], the occurrence of stereotypies indicates compromised welfare, when individual animals spent more than $10 \%$ of their waking life performing stereotypies. Whether this was the case in individual animals in the present study cannot be determined for sure, as the frequency of stereotypies was only analyzed in detail at the herd level. However, stereotypies occurred during an average percentage of up to $17.0 \pm 1.8 \%$ of the scan intervals from $06: 00 \mathrm{~h}$ to 23:00 $\mathrm{h}$. This observation, as well as average figures of up to 0.9 stereotypies occurring per animal and hour, indicate that individual animals might have performed stereotypies during more than $10 \%$ of their waking life. Furthermore, it has to be taken into account that the data of the present study were acquired using scan sampling. Consequently, the real number of stereotypies is possibly even higher than observed. As stereotypies might be performed only for short periods of time, they are likely to be underestimated by the method of scan sampling due to the low possibility of short behavioral patterns occurring exactly at the sampling point [28].

Consistent with Sambraus et al. [22], Wierenga [23], and Graf [21], manipulation of objects was the most common stereotypy, being observed on average 0.1 to 0.5 times per animal and hour. In the literature as well as in the present study, tongue playing [22,23] as well as manipulation of conspecifics [21-23] occurred less often.

Over the course of a day, stereotypies mainly occurred during daylight hours. The low percentage of animals performing stereotypies during the night can be possibly explained by cattle being diurnal feeders with a nocturnal resting period [7,29]. There was a clear connection between periods with a high percentage of animals performing stereotypies and the periods of feed delivery, this being consistent with other studies (calves: [12,13,23], dairy cows: [30,31]). This temporal connection may support the observation of various authors in calves, heifers, and dairy cows that feed influences the occurrence of stereotypies [10,13-16,18,19,21]. Bergeron et al. [8] lists three hypotheses explaining the connection between feeding behavior and stereotypies in ungulates: Firstly, diets may not fully satisfy them, providing an insufficient gut fill or being deficient in some specific ways. Secondly, diets may take too little time to find, chew, or ruminate in comparison to natural diets, leading to unfulfilled feeding motivations of the animals, independent of gut fill. Thirdly, oral stereotypies may be an attempt to cope with low-fiber, carbohydrate-rich diets that negatively affect gut function. However, the occurrence of oral stereotypies in cattle is likely to be caused by a variety of factors [8,10]. Group 
size may be one of these. Leruste et al. [10] observed less manipulation of substrates and less tongue playing in calves housed in groups of more than 10 animals. In contrast, Gaude [11] observed more nutritive cross-sucking in calves housed in groups of more than 10 animals. In the present study, no clear influence of group size on the occurrence of oral stereotypies could be observed. There were differences between the different housing systems, but no obvious dependency on group size. Thus, the observed differences are more likely to be caused by other management factors that differed between groups, e.g., farm, space allowance, feeding management, or composition or particle size distribution of the TMR. As the groups observed in this study varied in various aspects, no clear conclusions can be drawn regarding the factors responsible for the development of stereotypies. To determine these, further experimental studies with comparable control groups are required.

The developments over the course of the fattening period also differed between the housing systems. In G14, there were no clear differences between the three OP, and the number of stereotypies per animal and hour stayed at an approximately constant level. In G33, the number of stereotypies slightly increased from OP1 to OP3, being consistent with the observations of Graf (1991) [21]. However, the developments in G16 and G22 were inverse: In G22, the values linearly decreased from OP1 to OP3 and in G16, they were clearly higher in OP1 than in OP2 and OP3. As G16 and G33 were housed on the same farm and received the same feed, neither group size nor feed composition nor management can be the only factor responsible for the development of stereotypies. The only noticeable difference between G16 and G33 was that G33 received additional straw in hayracks. This may explain the lower number of stereotypies occurring in G33 in comparison to G16 in OP1, as more structured feed is likely to reduce the occurrence of stereotypies $[10,15,16,19,21]$. Nonetheless, it cannot serve as a sound explanation for the values being considerably lower in OP2 and OP3 than in OP1 in G16, nor for the increasing values from OP1 to OP3 in G33. These differences are possibly caused by differing rearing conditions, as the animals originated from different farms. Consistently, Mason [1] stated that stereotypies once developed may be performed later in life in circumstances where the animal's wellbeing is not at stake. Therefore, the high level of stereotypies observed in this study cannot be interpreted as clear evidence of certain housing systems not being suitable for meeting the animal's needs. However, they clearly indicate that oral stereotypies are highly prevalent in fattening bulls housed under different conditions. As the occurrence of stereotypies may indicate restrictions in animal welfare occurring at some point in the animal's life, there is an urgent need to further analyze the causation of stereotypies in order to find ways of reducing their frequency.

Author Contributions: Conceptualization, L.S. and B.S.; data curation, L.S.; formal analysis, L.S., B.S. and N.K.; funding acquisition, N.K.; investigation, L.S.; methodology, L.S. and B.S.; project administration, B.S. and N.K.; supervision, B.S. and N.K.; visualization, L.S.; writing-original draft, L.S.; writing-review and editing, B.S. and N.K. All authors have read and agreed to the published version of the manuscript.

Funding: This research was funded by the Ministry for Science and Culture of Lower Saxony, Germany within the framework of the doctoral program "Animal welfare in Intensive Livestock production systems". This publication was supported by Deutsche Forschungsgemeinschaft and University of Veterinary Medicine Hannover, Foundation within the funding program Open Access Publishing.

Acknowledgments: The authors wish to thank the participating farm staff for their kind assistance. Special thanks go to Kai Göbel for his technical support.

Conflicts of Interest: The authors declare no conflict of interest. The funders had no role in the design of the study; in the collection, analyses, or interpretation of data; in the writing of the manuscript, or in the decision to publish the results.

\section{References}

1. Mason, G.J. Stereotypies and suffering. Behav. Process. 1991, 25, 103-115. [CrossRef]

2. Broom, D.M. Stereotypies as animal welfare indicators. In Indicators Relevant to Farm Animal Welfare; Smidt, D., Ed.; Martinus Nijhoff: Boston, MA, USA, 1983; pp. 81-87.

3. Wiepkema, P.R.; Broom, D.M.; Duncan, I.J.H.; van Putten, G. Abnormal Behaviours in Farm Animals; Commission of the European Communities: Brussels, Belgium, 1983. 
4. Mason, G. Stereotypic Behaviour in Captive Animals: Fundamentals and Implications for Welfare and Beyond. In Stereotypic Animal Behaviour: Fundamentals and Applications to Welfare, 2nd ed.; Mason, G., Rushen, J., Eds.; CABI: Wallingford, UK, 2006; pp. 325-356.

5. Council of Farm Animal Welfare. The Five Freedoms; Council of Farm Animal Welfare: London, UK, 1979.

6. Moran, J.; Doyle, R. Cattle Behaviour. In Cow Talk: Understanding Dairy Cow Behaviour to Improve Their Welfare on Asian Farms; CSIRO Publishing: Clayton South, Australia, 2015; pp. 37-67.

7. Philipps, C. Cattle Behaviour and Welfare, 2nd ed.; Blackwell Science Ltd.: Oxford, UK, 2002.

8. Bergeron, R.; Badnell-Waters, A.J.; Lambton, S.; Mason, G. Stereotypic oral behaviour in captive ungulates: Foraging, diet and gatrointestinal function. In Stereotypic Animal Behaviour. Fundamentals and Applications to Welfare, 2nd ed.; Mason, G., Rushen, J., Eds.; CABI: Wallingford, UK, 2006; pp. 19-57.

9. Winckler, C. Verhalten der Rinder. In Nutztierethologie; Hoy, S., Ed.; Verlag Eugen Ulmer: Stuttgart, Germany, 2009; pp. 78-103.

10. Leruste, H.; Brscic, M.; Cozzi, G.; Kemp, B.; Wolthuis-Fillerup, M.; Lensink, B.J.; Bokkers, E.A.M.; van Reenen, C.G. Prevalence and potential influencing factors of non-nutritive oral behaviors of veal calves on commercial farms. J. Dairy Sci. 2014, 97, 7021-7030. [CrossRef]

11. Gaude, I. Besaugen bei Kälbern der Rasse Deutsches Fleckvieh: Risikofaktoren und Bedeutung der individuellen Stressreaktion; University of Veterinary Medicine Hannover, Foundation: Hannover, Germany, 2014.

12. Bokkers, E.A.M.; Koene, P. Activity, oral behaviour and slaughter data as welfare indicators in veal calves: A comparison of three housing systems. Appl. Anim. Behav. Sci. 2001, 75, 1-15. [CrossRef]

13. Veissier, I.; Ramirez de la Fe, A.R.; Pradel, P. Nonnutritive oral activities and stress responses of veal calves in relation to feeding and housing conditions. Appl. Anim. Behav. Sci. 1998, 57, 35-49. [CrossRef]

14. Webb, L.E.; Bokkers, E.A.M.; Engel, B.; Gerrits, W.J.J.; Berends, H.; van Reenen, C.G. Behaviour and welfare of veal calves fed different amounts of solid feed supplemented to a milk replacer ration adjusted for similar growth. Appl. Anim. Behav. Sci. 2012, 136, 108-116. [CrossRef]

15. Webb, L.E.; Bokkers, E.A.M.; Heutinck, L.F.M.; Engel, B.; Buist, W.G.; Rodenburg, T.B.; Stockhofe-Zurwieden, N.; van Reenen, C.G. Effects of roughage source, amount, and particle size on behavior and gastrointestinal health of veal calves. J. Dairy Sci. 2013, 96, 7765-7776. [CrossRef]

16. Kooijman, J.; Wierenga, H.K.; Wiepkema, P.R. Verhaltensanomalien bei Mastkälbern in Gruppenhaltung mit und ohne Rauhfutteraufnahmemöglichkeit. Aktuelle Arb. Zur Artgemäßen Tierhalt. 1989, KTBL-Schrift 342, 94-107.

17. Redbo, I.; Jacobsson, K.G.; van Doorn, C.; Pettersson, G. A note on relations between oral stereotypies in dairy cows and milk production, health and age. Anim. Sci. 1992, 54, 166-168. [CrossRef]

18. Redbo, I.; Emanuelson, M.; Lundberg, K.; Oredsson, N. Feeding level and oral stereotypies in dairy cows. Anim. Sci. 1996, 62, 99-206. [CrossRef]

19. Redbo, I.; Nordblad, A. Stereotypies in heifers are affected by feeding regime. Appl. Anim. Behav. Sci. 1997, 53, 193-202. [CrossRef]

20. EFSA Panel on Animal Health and Welfare. Scientific Opinion on the welfare of cattle kept for beef production and the welfare in intensive calf farming systems. EFSA J. 2012, 10. [CrossRef]

21. Graf, B.P. Orale Ersatzaktivitäten bei Mastbullen-Auftreten, Ontogenese und Ursachen. In KTBL-Schrift 351: Aktuelle Arbeiten zur Artgemäßen Tierhaltung; KTBL: Münster-Hiltrup, Germany, 1991; Volume KTBL-Schrift 351, pp. 37-48.

22. Sambraus, H.H.; Kirchner, M.; Graf, B. Verhaltensstörungen bei der Futternaufnahme intensiv gehaltener Mastbullen. In KTBL-Schrift 299: Aktuelle Arbeiten zur artgemäßen Tierhaltung; KTBL: Münster-Hiltrup, Germany, 1983; Volume KTBL-Schrift 299, pp. 256-263.

23. Wierenga, H.K. Behavioural problems in fattening bulls. In Welfare Aspects of Housing Systems for Veal Calves and Fattening Bulls; Schlichting, M.C., Smidt, D., Eds.; Commission of the European Communities: Brussels, Belgium, 1987; pp. 105-122.

24. Anonymous. Tierschutzgesetz (TierSchG) in der Fassung der Bekanntmachung vom 18. Mai 2006 (BGBl. I S. 1206, 1313), das zuletzt durch Artikel 101 des Gesetzes vom 20. November 2019 (BGBl. I S. 1626) Geändert Worden ist. Available online: http://www.gesetze-im-internet.de/tierschg/BJNR012770972.html (accessed on 23 December 2019). 
25. Anonymous. Tierschutz-Nutztierhaltungsverordnung (TierSchNutztV) in der Fassung der Bekanntmachung vom 22. August 2006 (BGBl. I S. 2043), die zuletzt durch Artikel 3 Absatz 2 des Gesetzes vom 30. Juni 2017 (BGBl. I S. 2147) Geändert Worden ist. Available online: http://www.gesetze-im-internet.de/tierschnutztv/ TierSchNutztV.pdf (accessed on 23 December 2019).

26. Ministry for Food, Agriculture and Consumer Protection of Lower Saxony. Tierschutzleitlinie für die Mastrinderhaltung; Ministry for Food, Agriculture and Consumer Protection of Lower Saxony: Hannover, Germany, 2018.

27. Council of Europe. Recommendation concerning Cattle. In European Convention for the Protection of Animals kept for Farming Purposes; Council of Europe: Strasburg, France, 1988.

28. Martin, P.; Bateson, P. Measuring Behaviour: An Introductory Guide, 3rd ed.; Cambridge University Press: Cambridge, UK, 2007.

29. Sambraus, H.H. Nutztierethologie: Das Verhalten landwirtschaftlicher Nutztiere-Eine Angewandte Verhaltenskunde für die Praxis; Verlag Paul Parey: Berlin, Germany; Hamburg, Germany, 1978.

30. Redbo, I. Changes in duration and frequency of stereotypies and their adjoining behaviours in heifers, before, during and after the grazing period. Appl. Anim. Behav. Sci. 1990, 26, 57-67. [CrossRef]

31. Sato, S.; Nagamine, R.; Kubo, T. Tongue-playing in tethered Japanese Black cattle: Diurnal patterns, analysis of variance and behaviour sequences. Appl. Anim. Behav. Sci. 1994, 39, 39-47. [CrossRef]

(C) 2019 by the authors. Licensee MDPI, Basel, Switzerland. This article is an open access article distributed under the terms and conditions of the Creative Commons Attribution (CC BY) license (http://creativecommons.org/licenses/by/4.0/). 